\title{
The relationship between seasonal snow cover in Japan and recent climatic change
}

\author{
MOTOKI NISHIMORI \\ Graduate School of Geoscience, University of Tsukuba, 1-1, Tennodai, Tsukuba, Ibaraki 305, Japan \\ RYUICHI KAWAMURA \\ National Research Institute for Earth Science and Disaster Prevention, 3-1, Tennodai, Tsukuba, Ibaraki 305, Japan
}

\begin{abstract}
Atmospheric circulation patterns associated with snowfall fluctuations in Japan are examined using a rotated empirical orthogonal function (EOF) analysis. We also compute correlation coefficients between the scores of EOF modes in the $500 \mathrm{hPa}$ geopotential height field of the Northern Hemisphere (NH) and amounts of snowfall in Japan on annual, monthly and pentad time scales. It is found that recent variability of snowfall amount in Japan is closely related to the long-term variations of large-scale circulation patterns. It is suggested that the dominance of teleconnection patterns such as Pacific/North American (PNA) and Northern Asian (NA) are responsible for the increase of snowfall in the coastal regions of the Sea of Japan during the cold period for Japan (1977-86).
\end{abstract}

\section{INTRODUCTION}

Recent studies which discuss the long-term fluctuations of various parameters in the global atmospheric circulation are focused on not only the 2-5 year scale, such as the El Niño-Southern Oscillation (ENSO) phenomenon, but also the interdecadal scale (e.g. Namias and others, 1988; Trenberth, 1990). As the snowfall in Japan is closely related to the Asian winter monsoon, it is expected that their long-term fluctuations would affect the snowfall amount in Japan.

Previous studies of the snowfall in Japan tended to confine their analysis to the spatio-temporal variability of snowfall, or the effect of mesoscale circulation on regional snowfall. Sugiyama (1987) investigated the variations of the daily snowfall in Japan utilizing an empirical orthogonal function (EOF) analysis, and computed the correlations between the leading eigenmodes of snowfall and the $500 \mathrm{hPa}$ geopotential height anomalies in the Northern Hemisphere (NH). The result clearly showed that the snowfall fluctuations in Japan are largely characterized by the anomalous $\mathrm{NH}$ circulations. Morinaga and Yasunari (1993) suggested that the Pacific/ North American (PNA) pattern, which is one of the major teleconnection patterns dominating in the $\mathrm{NH}$ winter, is partly responsible for recent warm and slight snow years since 1987 in Japan. Furthermore, it has been pointed out that recent global warming is associated with the dominance of the PNA pattern (e.g. Nitta and Yamada, 1989; Trenberth, 1990).

Thus, the purpose of this study is to clarify relationships between recent global-scale climatic change, i.e. interannual and interdecadal variability of the major teleconnection patterns, and snowfall fluctuation in Japan.

\section{RELATIONSHIP BETWEEN MAJOR GIRGULA- TION PATTERNS IN THE NH AND SNOWFALL IN JAPAN}

A rotated EOF analysis (see Richman, 1986) was applied to 5 day mean $500 \mathrm{hPa}$ geopotential height anomalies compiled by the Japan Meteorological Agency (JMA) in the $\mathrm{NH}$ cold season (October-March). The first ten modes are shown in Table 1 with abbreviations of the teleconnection patterns described by Barnston and Livezey (1987) and the percentage variance explained

Table 1. Abbreviations and per cent variance (\%) of the first ten EOF modes

Mode The names of circulation patterns Variance

NAO (North Atlantic Oscillation)

2 PNA (Pacific/North American) 6.5

3 WP (Western Pacific) 5.6

4 EP (Eastern Pacific) 5.3

$5 \quad$ NA (Northern Asian) 5.3

$6 \quad$ TP (Tibetan Plateau) 5.2

7 EU-1 (Eurasian Pattern Type 1) 5.0

8 EU-2 (Eurasian Pattern Type 2) 5.0

9 TNH (Tropical/Northern Hemisphere) 4.1

10 EA (Eastern Atlantic) 4.0

Total 


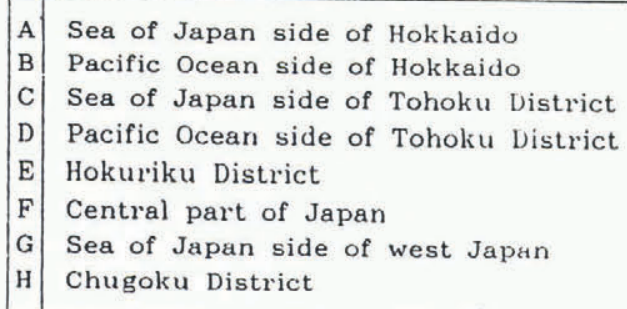

Fig. 1. Regional classification in area with frequent snowfall in Japan. Representative observation stations in each region are shown by large circles and the other stations are shown by small circles.

by each mode. The first ten modes account for more than half of the total variance.

To clarify the regionality of snowfall variability, correlation statistics were applied to annual and monthly amounts of snowfall at $30 \mathrm{JMA}$ observation stations in the area of Japan with frequent snowfall. (The snowfall data is also provided by JMA.) The area was first divided into two large regions: facing the Sea of Japan and facing the Pacific Ocean. These two regions were subdivided into four smaller regions (Fig. 1). Each of the eight smaller regions contains $2-5$ representative observation stations.

To find the circulation patterns which are closely associated with snowfall in Japan, we computed the correlation coefficients between the principal component scores of each EOF mode and regional averaged snowfall on annual, monthly and pentad time scales. It is clearly seen that five out of ten modes were significantly correlated with the snowfall amount in Japan. We utilized these five eigenmodes for the further analysis. Spatial structure of these low-frequency modes is shown in Figure 2. The correlation coefficients between time coefficients of the five modes and the annual and monthly snowfall amount are shown in Tables 2 and 3, respectively. Figure 3 shows the distribution of the significant level of the correlation coefficients for pentad snowfall of 30 stations. 

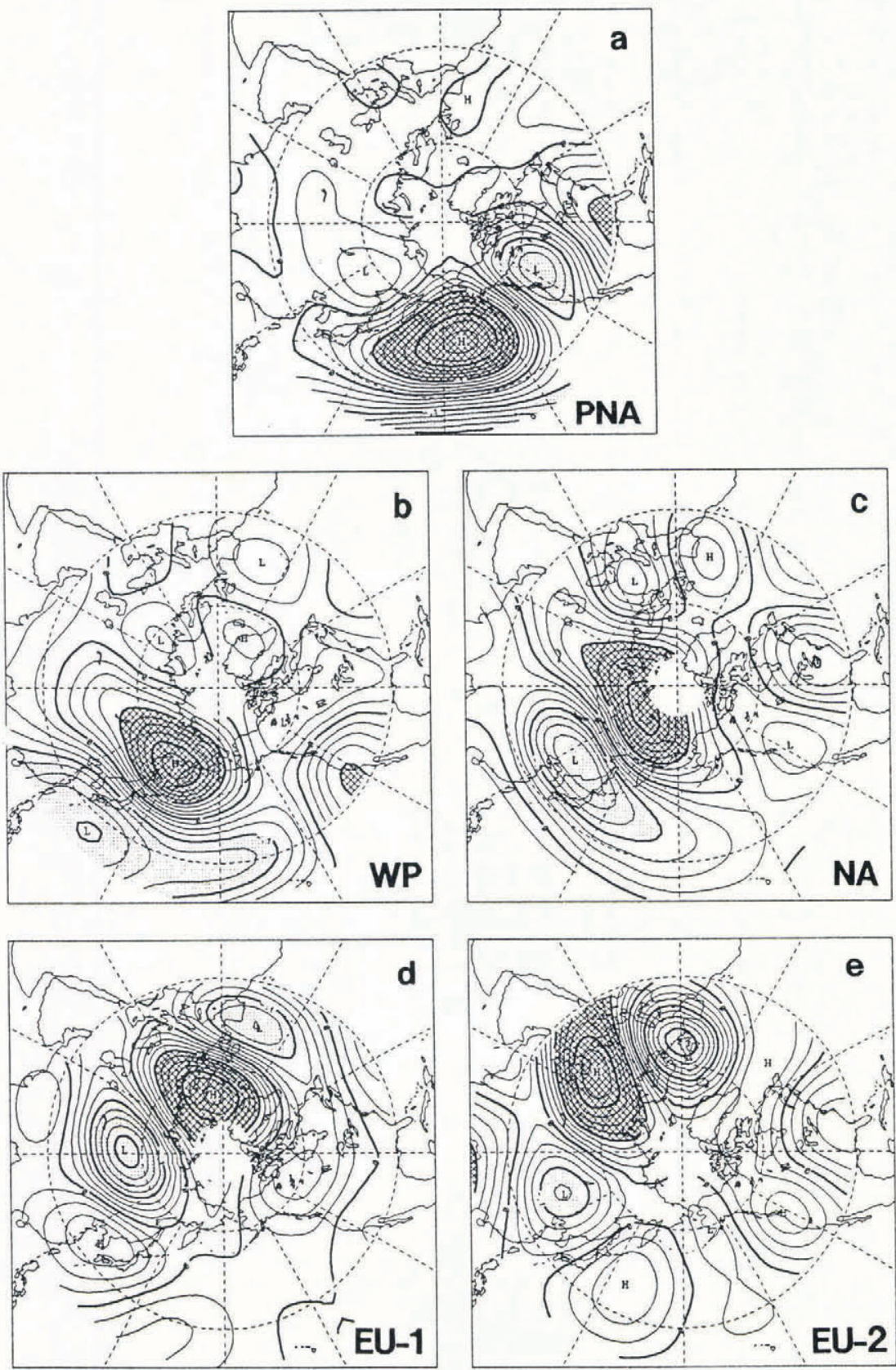

Fig. 2. Spatial patterns of the leading rotated EOF modes of $500 \mathrm{hPa}$ geopotential height anomalies during the Northern Hemisphere cold season (October-March) from 1946-89 associated with snowfall in Japan. Contour interval is 0.025 in relative units and negative values are denoted by dashed lines. Heavy and light shadings denote significant positive and negative anomalies, respectively. $a, P N A ; b, W P ; c, \mathcal{N} A ; d, E U-1 ; e, E U-2$.

Table 2. Correlation coefficients between component scores of circulation patterns and annual snowfall of each region

\begin{tabular}{|c|c|c|c|c|c|c|c|c|}
\hline & $A$ & $B$ & $C$ & & $E$ & $F$ & $G$ & $H$ \\
\hline PNA & -0.33 & -0.21 & -0.21 & -0.29 & $-0.38^{*}$ & -0.27 & -0.35 & -0.09 \\
\hline WP & -0.07 & -0.07 & 0.38 & 0.13 & 0.29 & 0.36 & 0.10 & $0.56^{* *}$ \\
\hline NA & $0.66^{* *}$ & $0.39^{*}$ & $0.61^{* * *}$ & 0.29 & $0.58^{* *}$ & 0.21 & $0.59^{* *}$ & 0.12 \\
\hline EU-1 & 0.06 & 0.19 & -0.08 & 0.19 & -0.01 & -0.23 & 0.03 & -0.08 \\
\hline EU-2 & $0.40^{*}$ & $0.41^{*}$ & $0.40^{\circ}$ & 0.18 & $0.47^{*}$ & 0.15 & $0.64^{* *}$ & 0.32 \\
\hline
\end{tabular}

"*: significant at $1 \%$ level; ": significant at $5 \%$ level. 
Table 3. Correlation coefficients between the scores of each circulation pattern and monthly snowfall of each region: (a)

PNA pattern, (b) WP pattern, and (c) NA pattern

\begin{tabular}{|c|c|c|c|c|c|c|c|c|}
\hline \multirow{2}{*}{$\begin{array}{l}\text { (a) } \\
\text { PNA }\end{array}$} & & \multicolumn{7}{|c|}{ Region } \\
\hline & $A$ & $B$ & C & $D$ & $E$ & $F$ & $G$ & $H$ \\
\hline Nov. & 0.06 & 0.07 & 0.30 & 0.18 & $0.45^{*}$ & 0.18 & 0.29 & \\
\hline Dec. & -0.36 & -0.28 & -0.10 & -0.10 & -0.10 & -0.09 & -0.08 & -0.16 \\
\hline Jan. & -0.14 & 0.05 & -0.15 & -0.12 & -0.30 & -0.03 & -0.22 & -0.19 \\
\hline Feb. & -0.33 & 0.04 & $0.64^{* *}$ & -0.27 & $-0.75^{* *}$ & $-0.42^{*}$ & $-0.68^{* *}$ & $-0.46^{*}$ \\
\hline Mar. & $-0.42^{*}$ & -0.24 & $-0.41^{*}$ & -0.25 & $-0.45^{*}$ & -0.33 & -0.27 & -0.21 \\
\hline
\end{tabular}

(b)

WA

$A$

$B$

C

D Region

E

F

$H$

\begin{tabular}{|c|c|c|c|c|c|c|c|c|}
\hline Nov. & -0.28 & -0.27 & 0.08 & -0.17 & -0.05 & -0.07 & -0.02 & \\
\hline Dec. & -0.12 & -0.22 & 0.21 & $0.40^{*}$ & 0.15 & 0.36 & 0.03 & 0.03 \\
\hline Jan. & -0.10 & 0.24 & $0.46^{*}$ & -0.06 & $0.38^{*}$ & $0.45^{*}$ & 0.31 & $0.61^{* *}$ \\
\hline Feb. & -0.08 & 0.00 & 0.32 & 0.13 & 0.29 & 0.20 & 0.07 & $0.50^{* *}$ \\
\hline Mar. & -0.34 & 0.14 & -0.25 & -0.18 & -0.11 & 0.13 & -0.07 & -0.03 \\
\hline
\end{tabular}

(c)

NA

A $\quad B$

C

$D^{\quad \text { Region }}{ }_{E}$

F

G

$H$

\begin{tabular}{lllllllll} 
Nov. & $0.57^{* *}$ & 0.18 & $0.51^{* *}$ & 0.29 & 0.11 & 0.05 & 0.05 & \\
Dec. & $0.60^{* *}$ & 0.22 & $0.48^{* *}$ & $0.49^{* *}$ & $0.54^{* *}$ & $0.50^{* *}$ & $0.45^{* *}$ & 0.30 \\
Jan. & $0.55^{* *}$ & -0.04 & $0.71^{* *}$ & 0.07 & $0.66^{* *}$ & 0.33 & $0.58^{* *}$ & 0.05 \\
Feb. & $0.55^{* *}$ & $0.38^{* *}$ & $0.40^{* *}$ & 0.20 & $0.39^{*}$ & 0.22 & $0.51^{* *}$ & 0.08 \\
Mar. & $0.54^{* *}$ & 0.08 & $0.51^{* *}$ & -0.06 & $0.38^{*}$ & 0.26 & $0.39^{*}$ & -0.03 \\
\hline
\end{tabular}

"*: significant at $1 \%$ level; ": significant at $5 \%$ level. No snowfall in November in Region H.

The PNA pattern (Fig. 2a) is negatively correlated to monthly snowfall mainly in the western part of Japan (Regions E, F, G and H) for February (Table 3a), and negatively correlated to annual snowfall only in Region $\mathrm{E}$ (Table 2). Large positive anomalies of geopotential height are located in the North Pacific, which seems to be associated with the behavior of the Aleutian Low. When the EOF score shows negative value, a deepened Aleutian Low may intensify the Asian winter monsoon, and as a consequence, bring out snowfall in Japan.

In both the Western Pacific (WP) pattern (Fig. 2b) and the Northern Asian (NA) pattern (Fig. 2c), large areas of positive anomalies in geopotential height field are observed in the northern region of the Far East, whereas the negative anomalies are found in the southern region including Japan. When the EOF scores of the two patterns have positive values, the westerly jet around Japan tends to shift southward and to meander there, and thereby cold air mass intrudes into Japan to bring snowfall. That is, generally the WP and NA patterns are positively correlated with the snowfall amount of Japan.

However, a noteworthy difference between the WP and NA teleconnection patterns is the position of northsouth dipole centers. Two anomalous centers of the WP pattern are located more southward than those of the NA pattern. Furthermore, it can be seen in the WP pattern that the boundary between positive and negative anomalies exists over the north of Japan. Therefore, the WP pattern is strongly connected with the snowfall only in Region $\mathrm{H}$ in the west of Japan (Table 2), especially in midwinter (Table $3 \mathrm{~b}$ ). However, it is seen in the other regions that the correlations are not so significant. On the other hand, the NA pattern has significant positive correlations to the snowfall fluctuations in the coastal regions of the Sea of Japan (Regions A, C, E and G) on interannual and intermonthly time scales. Especially, high correlations are found between them over winter months in northern Japan (Tables 2 and 3c).

The Eurasian pattern type 1 (EU-1, Fig. 2d) does not 


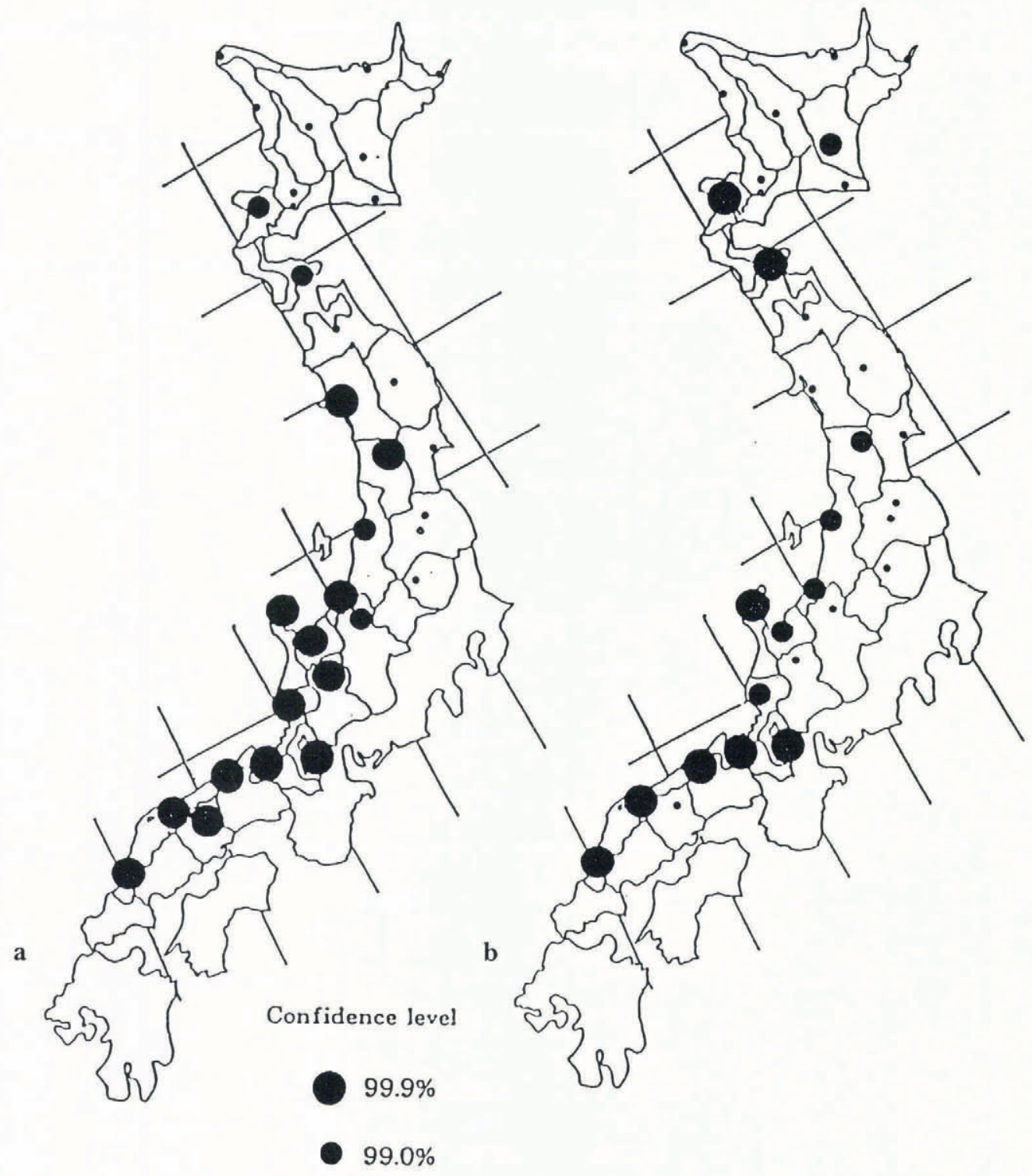

Fig. 3. Confidence level in the correlation coefficient between EOF scores and pentad snowfall in each station. Large and small circles show confidence level $99.9 \%$ and $99.0 \%$, respectively. a, simultaneous correlation coefficients between the scores of EU-1 pattern and pentad snowfall. $b$, lag correlation coefficients between the scores of EU-2 pattern and pentad snowfall at a lag of one pentad. Positive lag implies that the fluctuation of snowfall lags the scores.

have any significant correlations to the annual and monthly snowfall amounts (Table 2), but it is correlated to the pentad snowfall amount in Regions C, E, F, G and H (Fig. 3a). The Eurasian pattern type 2 (EU-2, Fig. 2e) has a positive simultaneous correlation to the annual snowfall amount in the coastal regions of the Sea of Japan (Table 2), and a positive lag correlation to the pentad snowfall amount (EU-2 leads snowfall by one pentad) in Regions E and G (Fig. 3b). The EU-2 pattern is characterized by the positive center locating over the western North Pacific region near Japan and the negative center over China around $40-50^{\circ} \mathrm{N}$. It is suggested that this pattern enables a dominance of trough accompanied with cold air intruding into Japan. While the WP and NA patterns are correlated with the snowfall amount mainly on a seasonal scale, the EU-1 and EU-2 patterns are closely associated with the snowfall variability, especially on the intramonthly time scale.

\section{RECENT FLUCTUATIONS OF SNOWFALL AMOUNT IN JAPAN AND GLOBAL CLIMATIC CHANGE}

It has already been reported that the average winter surface temperature in the $\mathrm{NH}$ was low in the 1960s but has tended to rise since the early 1970s. In the early 1980s the temperature became persistently higher (e.g. Jones, 1988). In Japan, however, cold winters appeared frequently from the mid-1970s to the mid-1980s (Japan Meteorological Agency, 1989), and heavy snowfall often occurred in 1977-86. To investigate the different trend between $\mathrm{NH}$ and Japan average winter temperature, we defined the period 1977-86 as a cold period for Japan and the period $1964-73$ as a warm period for Japan.

The differences of the annual and monthly snowfall were computed in two periods utilizing student-T test. It is noted that we had much annual snowfall during the 
Table 4. Statistical values of $T$-test for the differences in the annual snowfall between cold period for Fapan (1977-86) and the warm period for Japan (1964-73). Positive and negative values show increase and decrease, respectively, of snowfall in the cold period

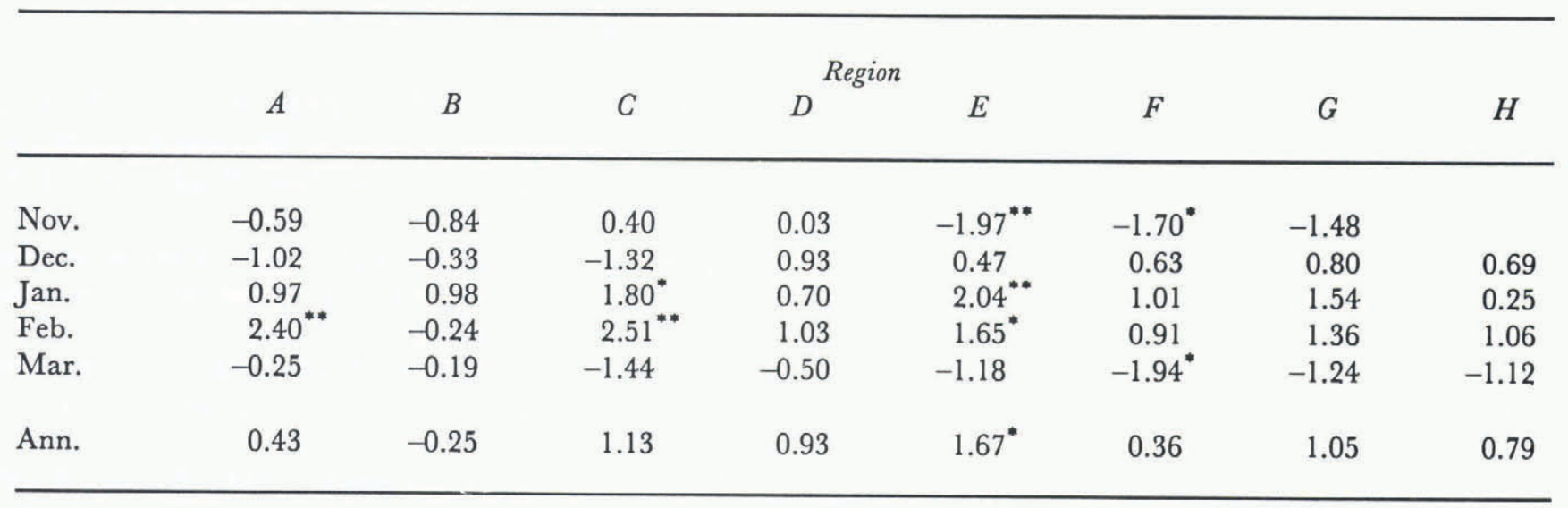

**: significant at $5 \%$ level; *: significant at $10 \%$ level. No snowfall in November in Region $\mathrm{H}$.

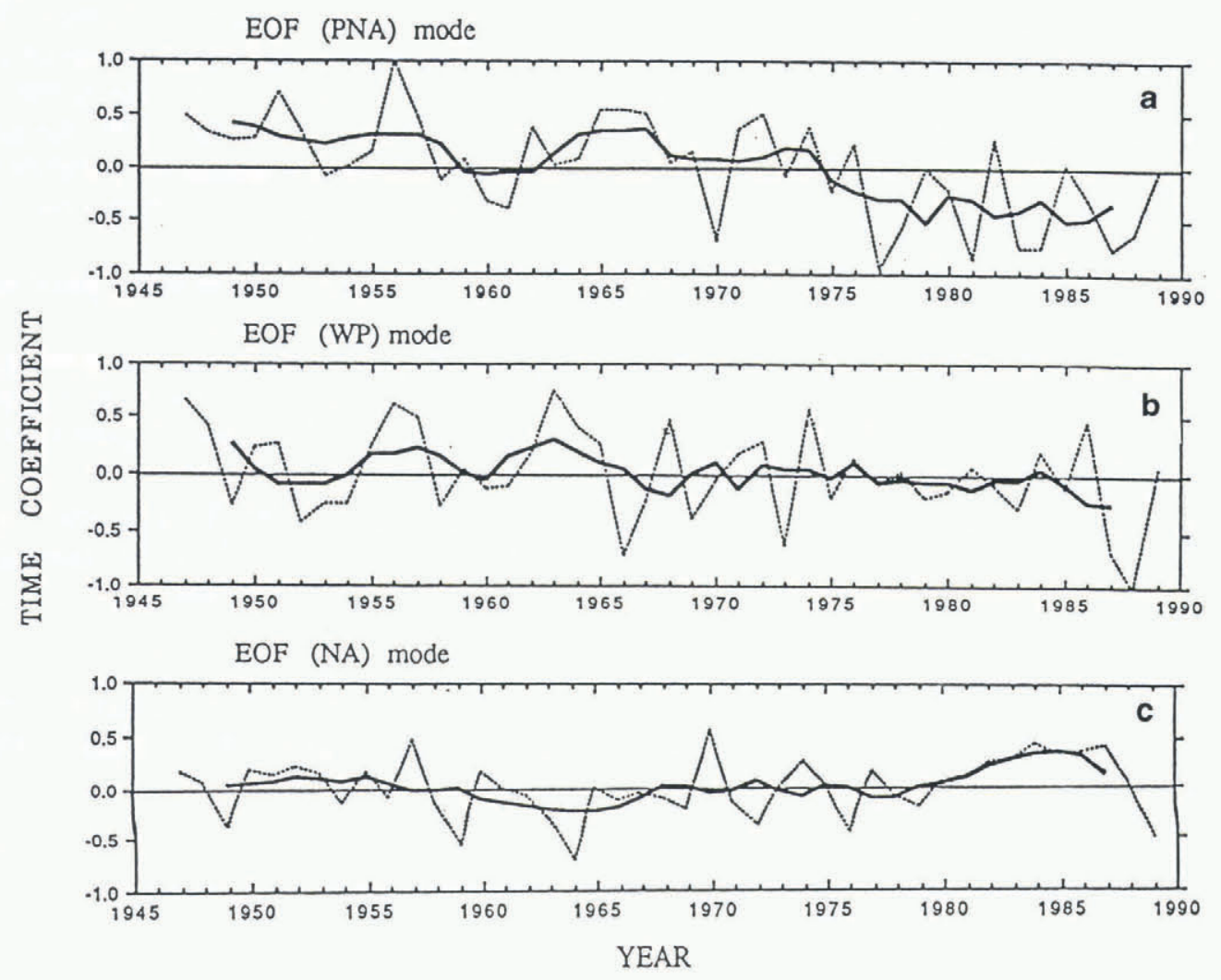

Fig. 4. Time coefficient (i.e. factor scores) averaged from October-March of $a, P \mathcal{N} A ; b, W P ; c, \mathcal{N} A$ patterns.

Fiveyear running mean values are denoted by heavy lines.

cold period in the coastal regions of the Sea of Japan, especially in Region E, where the snowfall was affected by the PNA and NA patterns (Table 4). Although the snowfall in November and March had decreased, the snowfall in this region in January and February had increased. Therefore, the annual snowfall in Region $\mathrm{E}$ had increased during the cold period for Japan. On the other hand, in Region $\mathrm{H}$ the magnitude of increase trend of annual snowfall was not very large compared with that in Region E, where the snowfall was affected by the WP pattern.
Distinct features of large-scale circulation patterns in the cold period for Japan are that the negative PNA and the positive NA patterns were prominent, while the WP pattern was not prominent (Fig. 4). If we consider the above tendency of circulation patterns and the correlations to snowfall described in the previous section, the relationships between recent abnormal features appearing in major teleconnection patterns and the snowfall fluctuation in Japan during the cold period are presented as follows: 
(1) The persistence of the PNA and NA patterns is responsible for the increase of snowfall in the cold period for Japan (1977-86) in Region E (Hokuriku District).

(2) No dominance of the WP pattern contributes significantly to the slight increase of snowfall in Region H (Chugoku District).

Since 1987, the snowfall amount in Japan has been decreasing remarkably in most of the regions over every winter month. Therefore, we should further examine the overall features of long-term fluctuations appearing in atmospheric circulation and snowfall in Japan after 1987.

\section{SUMMARY}

Results of the correlation statistics between the scores of EOF modes in $\mathrm{NH} 500 \mathrm{hPa}$ height field and the amount of snowfall in Japan on various scales indicate that the circulation patterns most associated with snowfall in Japan are PNA, NA, WP, EU-1 and EU-2. The NA pattern has the highest correlation with the snowfall in the coastal regions of the Sea of Japan, and the PNA pattern also has significant correlations. Moreover, the WP pattern is closely connected with snowfall only in the western part of Japan. It should be emphasized that these three major recurrent patterns have correlations to the seasonal snowfall. It is seen, on the other hand, that the EU-1 and EU-2 patterns have correlation mainly in the pentad snowfall. It is also found that the increase of snowfall in the recent cold period for Japan (1977-86) in Hokuriku District is characterized by the dominance of the PNA and NA patterns, while no dominance of the WP pattern contributes to the slight increase of the snowfall in the west of Japan.

\section{ACKNOWLEDGEMENTS}

The authors thank the JMA for providing the data of snowfall amount and $500 \mathrm{hPa}$ geopotential height. The authors are also indebted to Y. Morinaga of the University of Tsukuba for reviewing the manuscript.

\section{REFERENCES}

Barnston, A. G. and R.E. Livezey. 1987. Classification, seasonality and persistence of low-frequency atmospheric circulation patterns. Mon. Weather Rev., 115, 1083-1126.

Japan Meteorological Agency. 1989. Unusual weather report, 1984. Tokyo, Printing Office of Ministry of Finance. [In Japanese.]

Jones, P.D. 1988. Hemispheric surface temperature variations: recent trends and an update to 1987. $\mathcal{F}$. Climate, 1, 654-660.

Morinaga, Y. and T. Yasunari. 1993. Recent global warming and variations of winter snow cover in Japan. University of T sukuba. Institute of Geoscience. Science Report, Section A 14, 49-59.

Namias, J., X. Yuan and D. R. Cayan. 1988. Persistence of North Pacific sea surface temperature and atmospheric flow patterns. F. Climate, 1, 682-703.

Nitta, T. and S. Yamada. 1989. Recent warming of tropical sea surface temperature and its relationships to the Northern Hemisphere circulation. F. Meteorol. Soc. Jpn, 67, 359-374.

Richman, M. B. 1986. Rotation of principal components. 7. Climatol., 6, 293-335.

Sugiyama, T. 1987. The relationship between the regional distribution of snowfall in Japan and global circulation. (M.Sc. thesis, University of Tsukuba.) [In Japanese.]

Trenberth, K.E. 1990. Recent observed interdecadal climatic change in the Northern Hemisphere. Bull. Am. Meteorol. Soc., 71, 988-993.

The accuracy of references in the text and in this list is the responsibility of the authors, to whom queries should be addressed. 